\title{
Note on Orthography
}

Modern Turkish is written with a modified Latin script, most letters of which are read as in English. Where appropriate, I have used Modern Standard Turkish spellings for words in Turkish and Modern Standard Turkish transliterations for words in Ottoman Turkish. The letters pronounced differently from or not part of the English alphabet are as follows:

a a short $a$, as in lark

c $j$, as in jam

ç ch, as in child

e as in the first vowel of ever

$\mathrm{g}$ as in $\mathrm{get}$

g silent $g$, similar to an elision of vowels around the $\check{g}$

i ee, as in keep

$1 \quad i$ as in girl

$\mathrm{j} \quad g$, as in French gillette

o short $o$, as in open

$\ddot{0} \quad$ as in the French oeu of oeuvre

s sh, as in show

$\mathrm{u} \quad u$, similar to the short oo in foot

$\ddot{u} \quad$ as in the German $\ddot{u} b e r$ 
This page intentionally left blank 